\title{
Mitochondrial mutations in maternally inherited hearing loss
}

Hideki Mutai $^{1 \dagger}$, Takahisa Watabe $^{2 \dagger}$, Kenjiro Kosaki $^{3}$, Kaoru Ogawa $^{2}$ and Tatsuo Matsunaga ${ }^{{ }^{*}}$

\begin{abstract}
Background: Although the mitochondrial DNA (mtDNA) mutations m.1555A $>\mathrm{G}$ and m.3243A $>\mathrm{G}$ are the primary causes of maternally inherited sensorineural hearing loss (SNHL), several other mtDNA mutations are also reported to be associated with SNHL.

Methods: Screening of m.1555A > G and m.3243A > G mutations was performed for 145 probands. Nine probands fulfilled the following criteria: 1) bilateral and symmetric SNHL, 2) $\geq 4$ family members with SNHL with a maternal trait of inheritance in $\geq 2$ generations, 3) onset of SNHL before the age of 40 years, 4) high-frequency SNHL, and 5) no record of environmental factors related to SNHL. Sequencing of additional mtDNA regions was performed for five subjects meeting the clinical criteria, but the screening results were negative.

Results: Among the nine cases meeting the five clinical criteria detailed above, three had the m.1555A > G mutation in MTRNR1, one had a m.3243A > G mutation in MTTL1, and one case had a m.7511T > C mutation in MTTS1. In the family with the m.7511T > C mutation, penetrance of SNHL among maternally related subjects was 9/17 (53\%). The age at onset varied from birth (congenital) to adulthood. Hearing levels varied from normal to moderately impaired, unlike previously reported subjects with this mutation, where some maternal family members presented with profound SNHL. Family members with the m.7511T > C mutation and SNHL did not exhibit any specific clinical characteristics distinct from those of other individuals with SNHL and different mtDNA mutations. Among the 136 probands who did not meet the criteria detailed above, one case had the m.1555A > G mutation, and three cases had the m.3243A > G mutation.
\end{abstract}

Conclusions: Since five of nine probands with the clinical criteria used in this study had mtDNA mutations, these criteria may be helpful for identification of candidate patients likely to have mtDNA mutations.

Keywords: Mitochondrial deafness, Maternal inheritance, MTTS1

\section{Background}

Hearing loss is one of the most prevalent sensory disorders. Genetic factors are thought to account for more than half of congenital and childhood-onset hearing loss [1, 2], and mutations of mitochondrial DNA (mtDNA) are associated with maternally inherited sensorineural hearing loss (SNHL). Human mtDNA is a double-stranded, circular molecule, encoding 13 protein subunits, two ribosomal RNAs (rRNAs), and 22 transfer RNAs (tRNAs) [3]. Among the mutations in mitochondrial genes, m.1555A >

\footnotetext{
* Correspondence: matsunagatatsuo@kankakuki.go.jp

${ }^{\dagger}$ Equal contributors

${ }^{1}$ Division of Hearing and Balance Research, National Institute of Sensory Organs, National Hospital Organization Tokyo Medical Center, 2-5-1 Higashigaoka, Meguro, Tokyo 152-8902, Japan

Full list of author information is available at the end of the article
}

G in MTRNR1 (also known as 12SrRNA), and m.3243A > G in MTTL1 ( $\left.t R N A^{\operatorname{Leu}(U U R)}\right)$ are relatively frequent causes of SNHL [4]. The m.1555A > G mutation in MTRNR1 is associated with aminoglycoside ototoxicity and nonsyndromic SNHL, while MTTL1 m.3243A > G is associated with mitochondrial encephalomyopathy, lactic acidosis, and stroke-like episodes (MELAS); maternally inherited diabetes and deafness syndrome (MIDD); and chronic progressive external ophthalmoplegia (CPEO). In addition, several other mitochondrial mutations, including m.14 94C $>\mathrm{T}$ in MTRNR1, and m.7445A $>\mathrm{G}, 7472 \mathrm{insC}$, and $7511 \mathrm{~T}>\mathrm{C}$ in MTTS1 $\left(t R N A^{\operatorname{Ser}(U C N)}\right)$ have been associated with nonsyndromic SNHL [4]. Furthermore, m.8344A> G and m.8356T $>C$ mutations in MTTK $\left(t R N A^{L y s}\right)$ [5], the m.14709T > C mutation in MTTE $\left(t R N A^{G l u}\right)$ [6], and 
several variants in MTTH $\left(t R N A^{H i s}\right)$ [7] and MTTS2 $\left(t R N A^{\operatorname{Ser}(A G Y)}\right)$ [8] have also been confirmed, or are reported, as associated with nonsyndromic or syndromic SNHL.

The clinical features of mitochondrial hearing loss are: 1) maternal inheritance; 2) hearing loss is always sensorineural and primarily symmetrical, with involvement of the higher frequencies, or all frequencies; 3) variable penetrance and severity, even within families; and 4) in general, childhood onset (postlingually) [4].

In this study, we performed mtDNA mutation analysis on two rRNA and 22 tRNA genes, including MTRNR1, MTTL1, MTTS1, MTTK, MTTH, MTTS2, and MTTE, variants in which have previously been reported to be associated with SNHL. We also investigated the clinical characteristics of family members with the m.7511A $>C$ mutation. We propose criteria to identify candidate patients likely to have mitochondrial mutations.

\section{Methods}

\section{Subjects}

The present study included 171 consecutive subjects from 145 families who visited the Department of Otolaryngology at Keio University Hospital with complaints of hearing loss and were then referred to the Center for Medical Genetics for genetic evaluation. Based on the clinical features of mitochondrial deafness (as reviewed by Kokotas et al. [4]), patients were selected for comprehensive mtDNA analysis if they met the following clinical criteria: 1) bilateral and symmetric SNHL; 2) at least four family members with SNHL with a maternal trait of inheritance for at least two generations; 3) onset of SNHL before the age of 40 years; 4) high-frequency SNHL ( $215 \mathrm{~dB}$ difference in hearing levels between the means of 0.5 and $1 \mathrm{kHz}$ and the means of 4 and $8 \mathrm{kHz}$, assessed by pure-tone audiometry. Both "gently sloping" and "steeply sloping" audiograms were taken into account); and 5) no record of environmental factors related to hearing loss, such as infectious diseases, premature birth, or newborn meningitis. The audiometric configuration of criterion 4) and severity of hearing loss were determined according to the guidelines of the GENEDEAF study group (http://hereditaryhearingloss.org). Patients with a history of use of ototoxic drugs were included in this study, because some drugs are associated with mitochondrial SNHL. Kaplan-Meier curves were plotted using R platform.

\section{Genetic analysis}

Genomic DNA was extracted from blood samples using the Gentra Puregene Blood kit (QIAGEN, Hamburg, Germany). Detection of the m.1555A > G and m.3243A > $\mathrm{G}$ mutations in all 145 probands was performed by restriction fragment length polymorphism (RFLP) analysis, as previously described $[9,10]$. Samples from five subjects, who met the clinical criteria and were not found to have mtDNA mutations by RFLP, were subjected to mutation analysis of mtDNA regions, including two rRNA and 22 tRNA genes by nested PCR, as described in [11] with modification. The nested-PCR was performed using PrimeSTAR HS DNA polymerase (Takara Bio, Shiga, Japan) and the following program: $98^{\circ} \mathrm{C}$ for $10 \mathrm{~min}$; $37 \mathrm{cy}$ cles of $98{ }^{\circ} \mathrm{C}$ for $10 \mathrm{~s}, 62{ }^{\circ} \mathrm{C}$ for $10 \mathrm{~s}$, and $72{ }^{\circ} \mathrm{C}$ for $1 \mathrm{~min}$; and then $72{ }^{\circ} \mathrm{C}$ for $3 \mathrm{~min}$. PCR primers are listed in Additional file 1. Amplicons were sequenced using an ABI 3730 DNA sequence analyzer, using the ABI Prism Big Dye Terminator Cycle Sequencing kit (Applied Biosystems, MA, USA). Sequences were characterized using SeqScape software v2.6 (Applied Biosystems) and DNASIS Pro (Hitachisoft, Tokyo, Japan) with rCRS NC_012920.1.

\section{Results \\ mtDNA analysis}

Among 145 probands who visited the Department of Otolaryngology at Keio University Hospital, nine fulfilled the five clinical criteria detailed in the Methods section and were, therefore, analyzed for mtDNA mutations. Among these nine individuals, homoplasmic m.1555A > $\mathrm{G}$ and heteroplasmic m.3243A $>\mathrm{G}$ mutations were identified in three cases and a single case, respectively by RFLP analysis. Samples from the remaining five cases, who met the clinical criteria but did not have m.1555A $>$ G or m.3243A > G mutations, were subjected to Sanger sequencing analysis of mtDNA regions, including two rRNA and 22 tRNA genes, as described in the Methods section. One case had a homoplasmic (or a high level heteroplasmic) m.7511T $>C$ mutation in MTTS1 (Fig. 1). Other mtDNA variants detected in the five subjects are presented in Additional file 2. No novel or possible pathological mutations, nor any unknown variants, were detected in the remaining four subjects.

RFLP screening revealed homoplasmic m.1555A $>$ G and heteroplasmic m.3243A $>\mathrm{G}$ mutations in one and three patients, respectively, among 136 probands who failed to meet the five criteria. The clinical features of

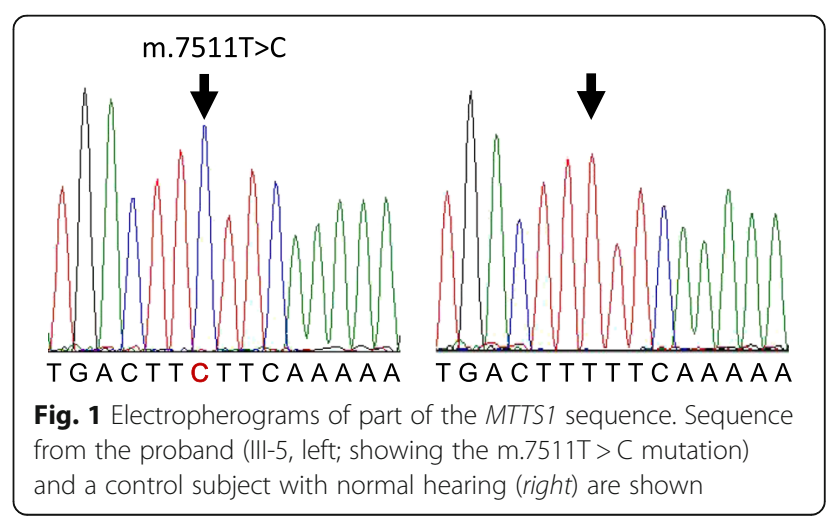


probands with the $\mathrm{m} \cdot 1555 \mathrm{~A}>\mathrm{G}$ and $\mathrm{m} \cdot 3243 \mathrm{~A}>\mathrm{G}$ mutations are presented in Additional file 3.

\section{Clinical findings in the family with the m.7511T $>C$ mutation}

In the family of the proband (III-5) carrying the m.7511T > C mutation, nine (I-2, II-3, II-8, III-1, III-3, III-5, IV-2, IV-3, and IV-6) of 17 maternally related members in four generations exhibited SNHL (Fig. 2). Subjects II-1, II-2, II-5, and II-7 died before they reached adulthood $(\geq 20 \mathrm{y})$ for reasons other than illness. The phenotypes of seven family members identified as carrying the m.7511T $>\mathrm{C}$ mutation by genetic analysis are presented in Table 1. Five subjects, III-3, III-5, IV-2, IV3 , and IV-6, were confirmed to have SNHL by pure-tone audiometry. The onset of SNHL was congenital in one subject (IV-6), during childhood in six subjects (II-3, II8, III-1, III-3, IV-2, and IV-3), and there was adult onset in one subject (III-5) (Table 1, Fig. 3). The severity of SNHL ranged from moderate in three subjects (III-3, III-5, and IV-3), to moderate or mild in each ear in one subject (IV-6), and mild in one subject (IV-2), whereas the other two subjects (III-7, IV-4) demonstrated normal hearing levels. The audiometric configuration was flat in one subject (IV-2), gently sloping in one ear and flat in the other ear in one subject (III-3), sloping in two subjects (III-5 and IV-3), and low-frequency SNHL was detected in one subject (IV-6). Three subjects (III-3, III-5, and IV-3) showed progression of SNHL, whereas the hearing levels of the other subjects (III-7, IV-2, IV-4, and IV-6) did not worsen. No subjects showed fluctuation of hearing. A speech discrimination test was performed for four subjects (III-3, III-5, IV-2, and IV-3) and distortionproduct otoacoustic emissions (DPOAE) were tested for six subjects (III-3, III-5, III-7, IV-2, IV-3, and IV-4). The speech discrimination test indicated that all subjects had $\geq 90 \%$ discrimination, other than one, who had discrimination of $85 \%$ in the left ear. DPOAE was abnormal at all, or some, tested frequencies in all subjects. These results are consistent with hearing loss caused by inner ear disorders. In addition to SNHL, subjects III-3 and III-5 exhibited vertigo and tinnitus, whereas the other individuals carrying the m.7511T $>C$ mutation did not present with additional symptoms.

\section{Discussion}

Among 145 probands, nine were analyzed for mtDNA gene mutations based on the presence of clinical features of mitochondrial SNHL. Five of these individuals were found to carry mutations (three cases with m.1555A $>$ G, one with m.3243A $>\mathrm{G}$, and one with m.7511T $>\mathrm{C}$ ). These results are in agreement with previous studies reporting that $\mathrm{m} .1555 \mathrm{~A}>\mathrm{G}$ and $\mathrm{m} .3243 \mathrm{~A}>\mathrm{G}$ are the highest frequency mtDNA mutations associated with SNHL, and that other SNHL-associated mtDNA mutations occur much less frequently $[4,11]$. These two most common mutations were detected in only $3 \%$ (one case of $\mathrm{m} .1555 \mathrm{~A}>\mathrm{G}$ and three cases of $\mathrm{m} .3243 \mathrm{~A}>\mathrm{G}$ ) of the 136 probands who did not meet the clinical criteria. These results suggest that the clinical criteria adopted in this study are helpful for selection of candidate patients with a high probability of carrying mtDNA mutations. No known pathogenic mutations, or unknown variants, were detected in the remaining mitochondrial rRNA and tRNA genes, including MTTK, MTTH, MTTS2, and MTTE, consistent with a previous report that MTTS1 is the third most frequent mtDNA region (after m.1555A > G in MTRNR1 and m.3243A > G in MTTL1) where mutations affecting auditory function occur [12].

Recent advances in next-generation sequencing technologies have enabled the identification of multiple nuclear genes responsible for hearing loss [13-15]. However, it is technically challenging to investigate mtDNA and nuclear DNA mutations simultaneously by next-generation sequencing, since mitochondrial genes are between two and three orders of magnitude more abundant than nuclear genes in the cell $[16,17]$. Therefore, pre-diagnostic selection of patients with a high

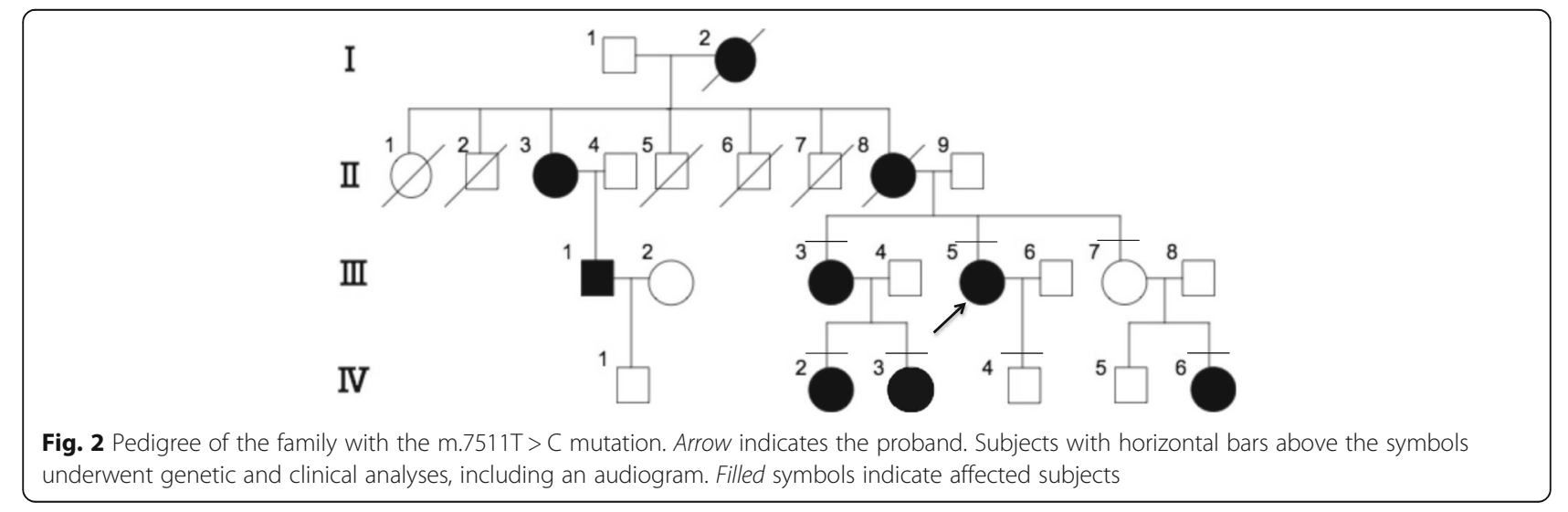


Table 1 Clinical features of family members carrying the m.7511T > C mutation

\begin{tabular}{|c|c|c|c|c|c|c|c|c|}
\hline Individual & Sex & $\begin{array}{l}\text { Age of onset } \\
\text { (years) }\end{array}$ & $\begin{array}{l}\text { Age at time of } \\
\text { test (years) }\end{array}$ & Severity (R/L) & $\begin{array}{l}\text { Audiometric } \\
\text { configuration (R/L) }\end{array}$ & Progression & $\begin{array}{l}\text { Speech } \\
\text { discrimination (R/L) }\end{array}$ & DPOAE \\
\hline$|1|-3$ & $\mathrm{~F}$ & 13 & 42 & Moderate/Moderate & Gently sloping/Flat & Yes & $95 \% / 85 \%$ & Bilateral NR \\
\hline |II-5 & $\mathrm{F}$ & 35 & 41 & Moderate/Moderate & $\begin{array}{l}\text { Gently sloping/ } \\
\text { Gently sloping }\end{array}$ & Yes & $90 \% / 95 \%$ & Bilateral NR \\
\hline$|1|-7$ & $\mathrm{~F}$ & - & 39 & Normal/Normal & NA & No & Not tested & $\begin{array}{l}\text { R: NR except } 1 \mathrm{kHz} \text {, } \\
\mathrm{L}: \mathrm{NR} \text { except } 1 \mathrm{kHz} \\
\text { and } 3 \mathrm{kHz}\end{array}$ \\
\hline IV-2 & $\mathrm{F}$ & 7 & 7 & Mild/Mild & Flat/Flat & No & $100 \% / 100 \%$ & $\mathrm{NR}$ at $4 \mathrm{kHz}$ \\
\hline IV-3 & $\mathrm{F}$ & 5 & 9 & Moderate/Moderate & $\begin{array}{l}\text { Steeply sloping/ } \\
\text { Gently sloping }\end{array}$ & Yes & $95 \% / 90 \%$ & Bilateral NR \\
\hline IV-4 & M & - & 22 & Normal/Normal & NA & No & Not tested & Bilateral NR \\
\hline IV-6 & $\mathrm{F}$ & 0 & 8 & Mild/Moderate & $\begin{array}{l}\text { Low frequency/ } \\
\text { Low frequency }\end{array}$ & No & Not tested & Not tested \\
\hline
\end{tabular}

$R$ right ear, $L$ left ear, $N R$ no response, $N A$ not applicable, DPOAE distortion-product otoacoustic emissions

probability of mitochondrial SNHL should contribute to the efficient analysis of mtDNA mutations.

At present, five MTTS1 variants, including m.7511T > C, are confirmed as, or suspected to be, associated with nonsyndromic or syndromic SNHL [4]. MTTS1 m.7511T > C has been identified in families with various ethnic backgrounds, including African-American, French, and Japanese (Table 2). The penetrance, severity, age of onset, and progression of SNHL across these families varies widely, making prediction of the effects of this mutation based on the clinical features of the patients difficult. The finding that patients in the family identified in this study with a

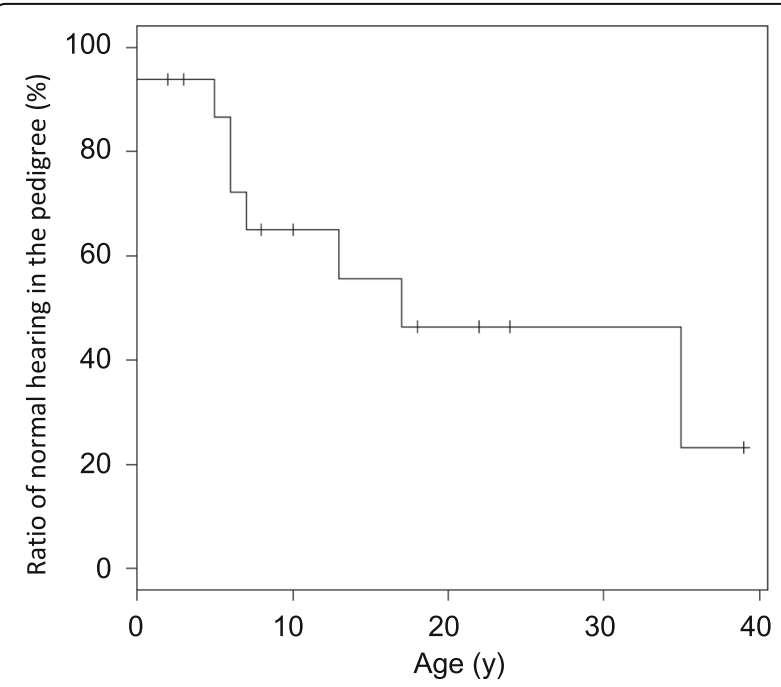

Fig. 3 Onset age of hearing loss in family members with the m.7511T > C mutation with a maternal pattern of inheritance. Sixteen subjects in this pedigree were included in the Kaplan-Meier analysis. Note that subject 1-2 was not included in the analysis due to insufficient clinical data. Vertical marks indicate censored subjects homoplasmic, or highly heteroplasmic, m.7511T > C mutation had phenotypes ranging from normal hearing to moderate levels of SNHL is unique compared with previous reports, where some maternal family members with homoplasmic and heteroplasmic m.7511T $>\mathrm{C}$ mutations exhibited profound SNHL (Table 2). The level of hearing loss of the proband (III-3) of the family with this mutation in the present study has remained moderate over 30 years, implying that severe hearing loss is not likely to develop before the onset of presbycusis in this family.

Among 17 maternally related individuals with the m.7511T $>\mathrm{C}$ mutation in the present study, nine had SNHL. However, the penetrance in this family (53\%) should be interpreted cautiously, because four subjects in generation II died before they reached adulthood. Considering the possibility that SNHL had yet to occur in subjects II-1, II-2, II-5, and II-7 at the time of their deaths, the actual penetrance of SNHL in this family is presumably higher than the calculated value. Consistent with this speculation, the penetrance in subjects in generation III and later was 6/ 9. Penetrance of SNHL in families with the m.7511T >C mutation in previous studies varied from approximately 30 to $84 \%$ [18-22]. Varying severity and penetrance have also been reported for m.1555A $>\mathrm{G}$ in MTRNR1 and m.7445A > G in MTTS1, which are frequent mitochondrial mutations associated with nonsyndromic SNHL [4, 23-29]. Future studies should investigate whether other mitochondrial DNA variants and/or haplotypes have modulatory effects on penetrance or phenotype severity in families with mtDNA mutations associated with SNHL.

\section{Conclusion}

Among the selected nine probands, five cases were determined to have pathogenic mtDNA mutations (three cases of m.1555A $>\mathrm{G}$, one of m.3243A $>\mathrm{G}$, and one of $\mathrm{m} .7511 \mathrm{~T}>\mathrm{C}$ ). The $\mathrm{m} .7511 \mathrm{~T}>\mathrm{C}$ mutation will be 
Table 2 Clinical features of previously reported pedigrees with the m.7511T > C mutation

\begin{tabular}{|c|c|c|c|c|c|c|c|}
\hline Ethnicity & Penetrance & Severity & $\begin{array}{l}\text { Age of onset } \\
\text { (years) }\end{array}$ & $\begin{array}{l}\text { Audiometric } \\
\text { configuration }\end{array}$ & Progression & $\begin{array}{l}\text { Homoplasmy/ } \\
\text { heteroplasmy }\end{array}$ & Reference \\
\hline African-American & $36 / 43(84 \%)$ & Unknown & Various & Unknown & Yes & Homo, hetero & {$[15]$} \\
\hline French & $7 / 19(37 \%)$ & Normal to profound & 3 to 33 & Unknown & Yes/Noa & Homo, hetero & [14] \\
\hline French & $6 / 19(32 \%)$ & Normal to profound & Various & Sloping, U-shaped & No & Homo, hetero & [14] \\
\hline Japanese & $13 / 24(54 \%)$ & Normal to profound & 3 to 30 & Sloping, dip, flat & Yes/No ${ }^{a}$ & High hetero & {$[16]$} \\
\hline Japanese & $7 / 23(30 \%)$ & Normal to profound & 26 to 45 & Sloping & Yes & Homo & [18] \\
\hline Japanese & 9/17 (53\%) & Normal to moderate & 0 to 40 s & Sloping, flat, low-frequency & Yes/No ${ }^{a}$ & Homo & This study \\
\hline
\end{tabular}

Homo, homoplasmy; hetero, heteroplasmy

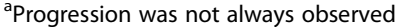

difficult to predict based on the variable clinical features of the patients with this mutation. The clinical criteria used in this study are considered helpful for the efficient identification of patients likely to have mtDNA mutations associated with SNHL.

\section{Additional files}

Additional file 1: Primers used in this study. (XLSX $11 \mathrm{~kb}$ )

Additional file 2: $m$ tDNA variants detected in 5 probands fulfilling the 5 criteria. (XLSX $12 \mathrm{~kb}$ )

Additional file 3: Clinical features of probands carrying m.1555A $>\mathrm{G}$ or m.3243A > G. (XLSX $11 \mathrm{~kb})$

\section{Abbreviations}

DPOAE: Distortion-product otoacoustic emissions; mtDNA: mitochondrial DNA; RFLP: Restriction fragment length polymorphism

\section{Acknowledgement}

We would like to thank Dr. Minako Sato at the Keio University School of Medicine for recruiting subjects.

\section{Funding}

This work was supported by a Grant-in-Aid for Clinical Research from the National Hospital Organization of Japan (H27-NHO (kankakuki)-02).

\section{Availability of data and materials}

The datasets supporting the conclusions of the article are included within the manuscript and Additional files.

\section{Authors' contributions}

HM carried out sequencing, analysis of DNA samples, and drafted the manuscript. TW collected and interpreted clinical data, and drafted the manuscript. KK and $\mathrm{KO}$ contributed to accumulation and interpretation of clinical and DNA data. TM designed the study, collected and interpreted clinical data, collected DNA samples, analyzed DNA data, and finalized the manuscript. All authors read and approved the final manuscript.

\section{Competing interests}

The authors declare that they have no competing interests.

\section{Consent for publication}

Written informed consent for publication was obtained from all subjects in the study or, for subjects under the age of 20 years, from their parents.

\section{Ethics approval and consent to participate}

This study was approved by the institutional ethics review boards at Keio University School of Medicine and National Hospital Organization Tokyo Medical Center. Written informed consent was obtained from each adult participant or from parents of child participants.

\section{Publisher's Note}

Springer Nature remains neutral with regard to jurisdictional claims in published maps and institutional affiliations.

\section{Author details}

${ }^{1}$ Division of Hearing and Balance Research, National Institute of Sensory Organs, National Hospital Organization Tokyo Medical Center, 2-5-1 Higashigaoka, Meguro, Tokyo 152-8902, Japan. ²Department of Otolaryngology, Head and Neck Surgery, Keio University School of Medicine, 35 Shinanomachi, Shinjuku, Tokyo 160-8582, Japan. ${ }^{3}$ Center for Medical Genetics, Keio University School of Medicine, 35 Shinanomachi, Shinjuku, Tokyo 160-8582, Japan.

Received: 31 May 2016 Accepted: 2 March 2017

Published online: 20 March 2017

\section{References}

1. Kral A, O'Donoghue GM. Profound deafness in childhood. N Engl J Med. 2010;363:1438-50

2. Morton CC, Nance WE. Newborn hearing screening-a silent revolution. N Engl J Med. 2006;354:2151-64.

3. Anderson S, Bankier AT, Barrell BG, de Bruijn MH, Coulson AR, Drouin J, et al. Sequence and organization of the human mitochondrial genome. Nature. 1981;290:457-65.

4. Kokotas H, Petersen MB, Willems PJ. Mitochondrial deafness. Clin Genet. 2007;71:379-91.

5. Shoffner JM, Lott MT, Lezza AM, Seibel P, Ballinger SW, Wallace DC. Myoclonic epilepsy and ragged-red fiber disease (MERRF) is associated with a mitochondrial DNA tRNA(Lys) mutation. Cell. 1990;61:931-7.

6. Hao H, Bonilla E, Manfredi G, DiMauro S, Moraes CT. Segregation patterns of a novel mutation in the mitochondrial tRNA glutamic acid gene associated with myopathy and diabetes mellitus. Am J Hum Genet. 1995;56:1017-25.

7. Yan X, Wang X, Wang Z, Sun S, Chen G, He Y, et al. Maternally transmitted late-onset non-syndromic deafness is associated with the novel heteroplasmic T12201C mutation in the mitochondrial tRNAHis gene. J Med Genet. 2011:48:682-90.

8. Leveque M, Marlin S, Jonard L, Procaccio V, Reynier P, Amati-Bonneau P, et al. Whole mitochondrial genome screening in maternally inherited nonsyndromic hearing impairment using a microarray resequencing mitochondrial DNA chip. Eur J Hum Genet. 2007:15:1145-55.

9. Matsunaga T, Hirota E, Bito S, Niimi S, Usami S. Clinical course of hearing and language development in GJB2 and non-GJB2 deafness following habilitation with hearing aids. Audiol Neurootol. 2006;11:59-68.

10. Usami S, Abe S, Akita J, Namba A, Shinkawa H, Ishii M, et al. Prevalence of mitochondrial gene mutations among hearing impaired patients. J Med Genet. 2000;37:38-40.

11. Mutai H, Kouike H, Teruya E, Takahashi-Kodomari I, Kakishima H, Taiji H, et al. Systematic analysis of mitochondrial genes associated with hearing loss in the Japanese population: $\mathrm{dHPLC}$ reveals a new candidate mutation. BMC Med Genet. 2011;12:135

12. Ding $Y$, Leng J, Fan F, Xia B, Xu P. The role of mitochondrial DNA mutations in hearing loss. Biochem Genet. 2013;51:588-602.

13. Brownstein Z, Friedman LM, Shahin H, Oron-Karni V, Kol N, Abu Rayyan A et al. Targeted genomic capture and massively parallel sequencing to 
identify genes for hereditary hearing loss in Middle Eastern families. Genome Biol. 2011;12:R89.

14. Mutai H, Suzuki N, Shimizu A, Torii C, Namba K, Morimoto N, et al. Diverse spectrum of rare deafness genes underlies early-childhood hearing loss in Japanese patients: a cross-sectional, multi-center next-generation sequencing study. Orphanet J Rare Dis. 2013;8:172

15. Shearer AE, DeLuca AP, Hildebrand MS, Taylor KR, Gurrola 2nd J, Scherer S, et al. Comprehensive genetic testing for hereditary hearing loss using massively parallel sequencing. Proc Natl Acad Sci U S A. 2010;107:21104-9.

16. Dames S, Chou LS, Xiao Y, Wayman T, Stocks J, Singleton M, et al. The development of next-generation sequencing assays for the mitochondrial genome and 108 nuclear genes associated with mitochondrial disorders. J Mol Diagn. 2013;15:526-34

17. Falk MJ, Pierce EA, Consugar M, Xie MH, Guadalupe M, Hardy O, et al. Mitochondrial disease genetic diagnostics: optimized whole-exome analysis for all MitoCarta nuclear genes and the mitochondrial genome. Discov Med. 2012;14:389-99.

18. Chapiro E, Feldmann D, Denoyelle F, Sternberg D, Jardel C, Eliot MM, et al. Two large French pedigrees with non syndromic sensorineural deafness and the mitochondrial DNA T7511C mutation: evidence for a modulatory factor. Eur J Hum Genet. 2002;10:851-6.

19. Friedman RA, Bykhovskaya Y, Sue CM, DiMauro S, Bradley R, FallisCunningham $R$, et al. Maternally inherited nonsyndromic hearing loss. Am J Med Genet. 1999;84:369-72.

20. Ishikawa K, Tamagawa Y, Takahashi K, Kimura H, Kusakari J, Hara A, et al. Nonsyndromic hearing loss caused by a mitochondrial T7511C mutation. Laryngoscope. 2002;112:1494-9.

21. Sue CM, Tanji K, Hadjigeorgiou G, Andreu AL, Nishino I, Krishna S, et al. Maternally inherited hearing loss in a large kindred with a novel $77511 \mathrm{C}$ mutation in the mitochondrial DNA tRNA(Ser(UCN)) gene. Neurology. 1999;52:1905-8.

22. Yamasoba T, Tsukuda K, Suzuki M. Isolated hearing loss associated with T7511C mutation in mitochondrial DNA. Acta Otolaryngol Suppl. 2007;559:13-8.

23. Ballana E, Morales E, Rabionet R, Montserrat B, Ventayol M, Bravo O, et al. Mitochondrial 125 rRNA gene mutations affect RNA secondary structure and lead to variable penetrance in hearing impairment. Biochem Biophys Res Commun. 2006;341:950-7.

24. Berrettini S, Forli F, Passetti S, Rocchi A, Pollina L, Cecchetti D, et al. Mitochondrial non-syndromic sensorineural hearing loss: a clinical, audiological and pathological study from Italy, and revision of the literature. Biosci Rep. 2008;28:49-59.

25. Casano RA, Bykhovskaya Y, Johnson DF, Hamon M, Torricelli F, Bigozzi M, et al. Hearing loss due to the mitochondrial A1555G mutation in Italian families. Am J Med Genet. 1998;79:388-91.

26. del Castillo FJ, Rodriguez-Ballesteros M, Martin Y, Arellano B, Gallo-Teran J, Morales-Angulo C, et al. Heteroplasmy for the 1555A> G mutation in the mitochondrial 125 rRNA gene in six Spanish families with non-syndromic hearing loss. J Med Genet. 2003;40:632-6.

27. Kupka S, Toth T, Wrobel M, Zeissler U, Szyfter W, Szyfter K, et al. Mutation A1555G in the 125 rRNA gene and its epidemiological importance in German, Hungarian, and Polish patients. Hum Mutat. 2002:19:308-9.

28. Scrimshaw BJ, Faed JM, Tate WP, Yun K. Rapid identification of an A1555G mutation in human mitochondrial DNA implicated in aminoglycosideinduced ototoxicity. J Hum Genet. 1999;44:388-90.

29. Jin L, Yang A, Zhu Y, Zhao J, Wang X, Yang L, et al. Mitochondrial tRNASer(UCN) gene is the hot spot for mutations associated with aminoglycoside-induced and non-syndromic hearing loss. Biochem Biophys Res Commun. 2007:361:133-9.

\section{Submit your next manuscript to BioMed Central and we will help you at every step:}

- We accept pre-submission inquiries

- Our selector tool helps you to find the most relevant journal

- We provide round the clock customer support

- Convenient online submission

- Thorough peer review

- Inclusion in PubMed and all major indexing services

- Maximum visibility for your research

Submit your manuscript at www.biomedcentral.com/submit

Biomed Central 